\title{
Diretrizes Ambientais para um Campus sustentável Avaliadas pela ótica do Design
}

\author{
Environmental Guidelines Evaluated through the Design point of view for a Sustainable \\ Campus
}

\author{
DEA JUNIOR, José Gilmar \\ Especialista; Universidade Positivo \\ josedeajr@hotmail.com \\ ROSA, Ivana Marques da \\ Especialista, Mestranda; Universidade Federal do Paraná \\ ivanamarques8@hotmail.com \\ SAMPAIO, Cláudio Pereira de \\ Mestre; Universidade Estadual de Londrina \\ qddesign@hotmail.com
}

\section{Resumo}

O campus universitário configura-se como um laboratório para boas práticas de sustentabilidade que, de acordo com Manzini (1994), pode contribuir na transição para estilos de vida mais sustentáveis, pois as experiências vivenciadas no campus poderão ser replicadas em toda a sociedade. Para tanto, este artigo foca na dimensão ambiental da sustentabilidade em campi universitários, a partir da ótica do design para a sustentabilidade e da visão sistêmica através do Sistema Produto Serviço - PSS. Os procedimentos metodológicos incluíram revisão bibliográfica, levantamento de boas práticas em dez campi universitários de diferentes continentes, e análise qualitativa através de ferramentas de PSS.

Palavras Chave: Diretrizes ambientais; Desenvolvimento sustentável; Campus universitário; Design.

\begin{abstract}
The university campus can be seen as a laboratory of best practices that, according Manzini 1994), can contribute to transition to more sustainable lifestyles, because the experiences lived at campus can be replyed oi the whole society. Therefore, this article focuses on the environmental dimension of sustainability in university campi, considering the design for sustainability point of view and the systemic view by the product service systems - PSS. The methodological approach includes theorical review, survey of best practices in 10 university campi of different continents, and qualitative analysis by means of PSS tools.
\end{abstract}

Keywords: Environmental guidelines; Sustainable development; University campus; Design. 


\section{Introdução}

Frente ao dinamismo do mundo contemporâneo, há uma grande urgência para identificar áreas de cooperação e ações conjuntas em favor do desenvolvimento sustentável. Nesse sentido, atentar-se para a significativa relevância de campi universitários, tendo em vista a riqueza desses espaços para intervenções em seu contexto, pode resultar em um trajeto mais curto para alcançarmos uma sociedade mais sustentável (ROCHA LOURES, 2009).

O uso do campus pode ser promovido como um laboratório experimental e como modelo de desenvolvimento sustentável para as comunidades exteriores ao campus, servindo assim de exemplo de boas práticas e comportamentos ambientais. Além disso, é possível idealizar e realizar um espaço adequado para a construção do conhecimento, para o fortalecimento das relações interpessoais, tornando-se um centro de referência para uma nova relação da sociedade com o meio ambiente (LAHAISE 2010).

É importante considerar uma mudança de paradigmas, onde poderão se formar não apenas profissionais de todas as áreas, mas cidadãos responsáveis que, através de sua experiência dentro de um "campus sustentável", replicarão esse aprendizado nos diversos âmbitos de suas vidas. A universidade tem condições de liderar a formação de uma sociedade, onde questões ambientais, sociais e econômicas estejam inseridas no cotidiano de forma integrada. O desenvolvimento sustentável como processo de aprendizagem pode abranger todas as escalas, envolvendo alunos, funcionários, professores, comunidade externa, etc (LAHAISE 2010).

Conforme Rocha Loures (2009), o caminho para solucionar o descaso diante de todos os problemas sócio-ambientais é a educação. Somente pessoas realmente educadas são capazes do julgamento necessário para examinar o seu cotidiano sob uma perspectiva ampla e coerente, incluindo na sua análise tudo aquilo que precisa ser incluído.

Portanto, existe nesse espaço, um grande potencial de inovação e efeitos multiplicadores de sua atuação. Nesse contexto, tem-se o design que, conforme International Council of Societies of Industrial Design - ICSID (2008), tem a missão de tomar conhecimento e avaliar as interconexões estruturais, organizacionais, funcionais, expressivas e econômicas com o objetivo de reforçar a sustentabilidade global e a proteção ambiental.

Assim, o design pode se tornar parte da solução dos problemas ambientais, sócioéticos e econômicos hoje enfrentados pela sociedade. Através de sua atuação frente a essas questões, pode contribuir na transição para estilos de vida mais sustentáveis, efetuando profunda mudança em sua cultura e sua práxis partindo do elementar redesenho de produtos existentes para a promoção de novos estilos de vida intrinsecamente sustentáveis (MANZINI, 1994).

Por tudo isso, o presente artigo tem como foco o recorte da dimensão ambiental da sustentabilidade em um campus universitário, bem como a proposta de abordagem do problema a partir do design para a sustentabilidade contemplando a visão sistêmica através da abordagem de PSS - Sistemas Produto Serviço.

\section{Método de Pesquisa}

Em um primeiro momento foi feita uma revisão bibliográfica com o objetivo de levantar os conceitos referentes ao design e a sustentabilidade; o design e o 
desenvolvimento sustentável; visão sistêmica através do PSS. Além das boas práticas sustentáveis e ferramentas voltadas, especificamente, a um campus sustentável.

Foram levantadas também, e organizadas na forma de um mapa mental ${ }^{1}$, atividades realizadas em campi sustentáveis das Américas, Ásia, Oceania, África e Europa. Destas universidades, foi feita uma análise qualitativa, que resultou em um quadro comparativo contemplando os pontos positivos e negativos sob a ótica da sustentabilidade ambiental. Estes dados foram levantados a partir de pesquisas nos próprios sites das instituições, revistas, livros, relatórios, artigos científicos e entre outros.

Os dados colhidos foram analisados, de forma qualitativa, através das etapas do método para o desenvolvimento do PSS, denominado MEPSS - Methodology for Product Service System (Figura 1). As ferramentas utilizadas são integrantes das duas primeiras fases do MEPSS, Análise Estratégica e Exploração de Oportunidades, e correspondem à Análise Swot, e ao Checklist. A Matriz de Impactos foi adaptada da metodologia D4S ${ }^{2}$

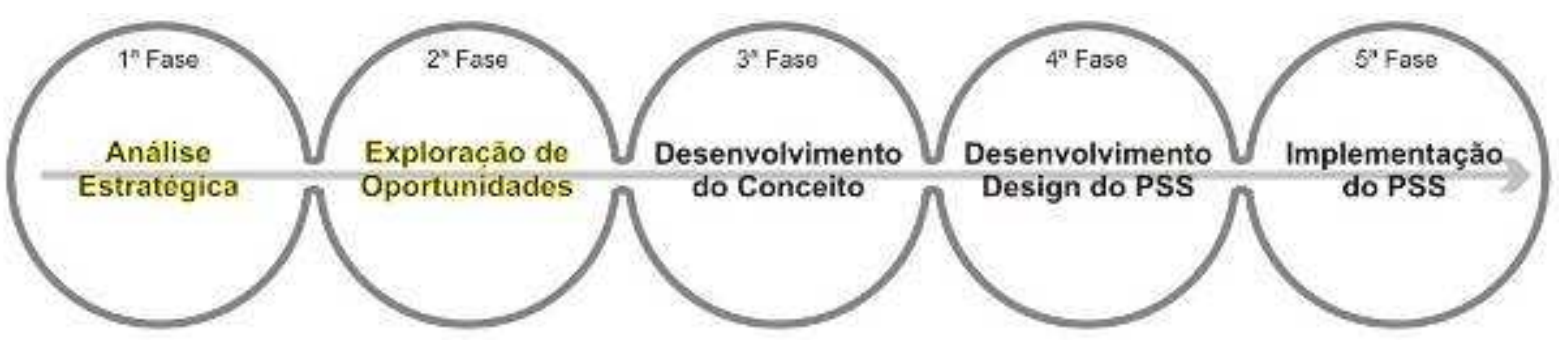

Figura 1 - Etapas do modelo MEPSS

Fonte: Adaptado de MEPSS (2010)

\section{O Design, a Sustentabilidade, e o Desenvolvimento Sustentabilidade}

$O$ design tem a missão de tomar conhecimento e avaliar as interconexões estruturais, organizacionais, funcionais, expressivas e econômicas com o objetivo de reforçar a sustentabilidade global e a proteção ambiental. Faz parte de seu papel, também, propiciar benefícios e liberdade para toda a comunidade humana, individual e coletiva, incluindo usuários, produtores e protagonistas do mercado; apoiando a diversidade cultural apesar da globalização mundial; fornecendo produtos, serviços e sistemas, que são as formas expressivas e coerentes com sua própria complexidade (ICSID, 2008).

Tendo em vista que a sustentabilidade, segundo Bardaglio (2007), envolve muito mais do que apenas minimizar o impacto negativo da atividade humana na biosfera, busca transmitir o conhecimento e promover o entendimento das causas ambientais; distribuir de forma mais justa recursos e poderes e uma economia saudável e, a soma desses fatores contribui para aumentar a qualidade de vida, abrangendo as dimensões ambiental, sócioética e econômica. Assim, a atuação do design pode trazer grandes contribuições, conforme a definição do ICSID (2008).

\footnotetext{
${ }^{1}$ Mapas mentais são representações gráficas com o objetivo de organizar e expor ideias para uma melhor visualização.

${ }^{2}$ A metodologia D4S foi desenvolvida pela Universidade de Delft (Holanda), em conjunto com a UNEP-ONU e, tem por objetivo facilitar o desenvolvimento a partir do design para a sustentabilidade.
} 


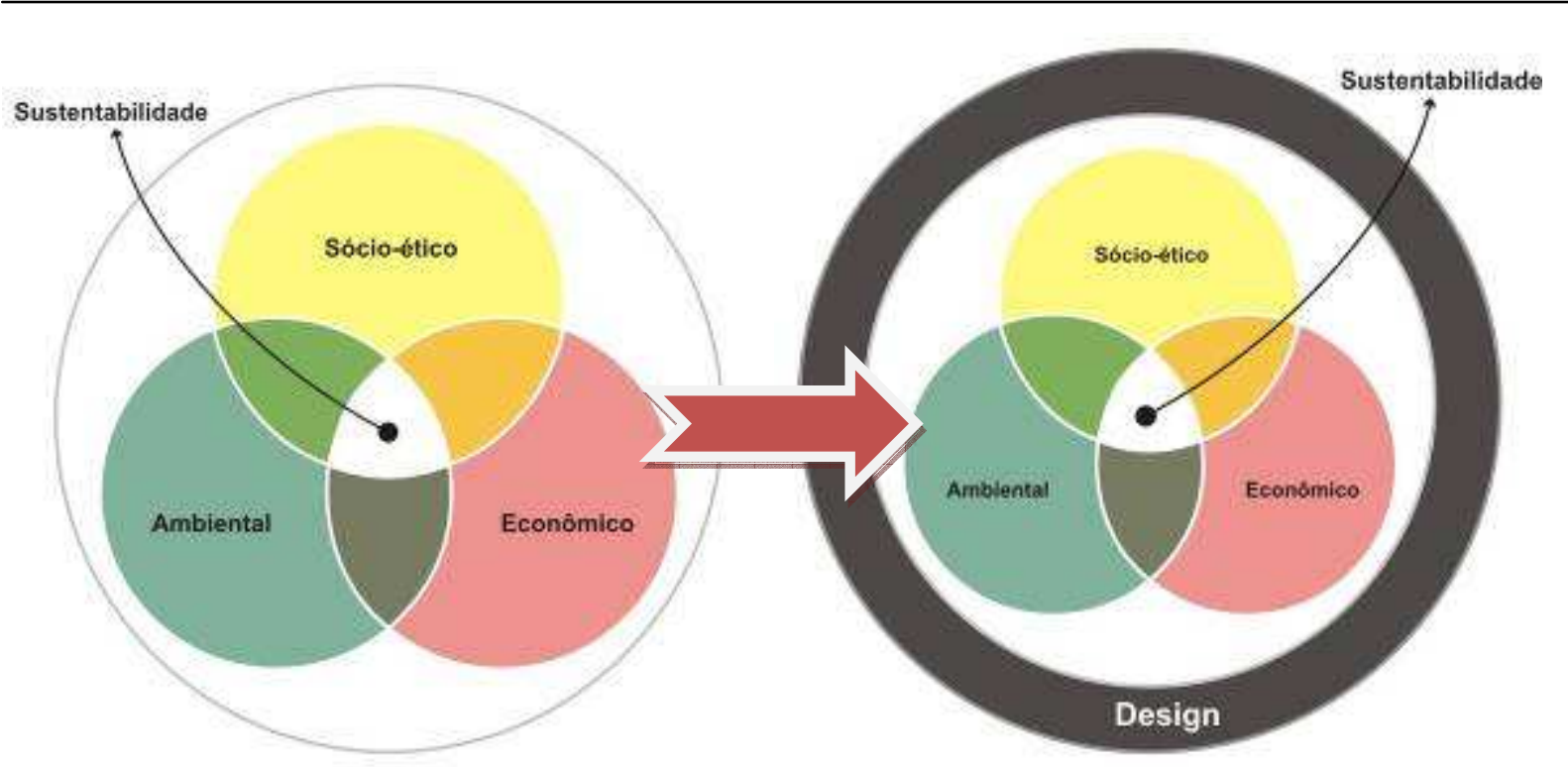

Figura 2 - Design e sustentabilidade

O design, portanto, pode se tornar parte da solução dos problemas ambientais, sócio-éticos e econômicos enfrentados pela sociedade contemporânea. Através de sua atuação frente a essas questões, pode contribuir na transição para estilos de vida sustentáveis, efetuando profunda mudança em sua cultura e sua práxis partindo do elementar redesenho de produtos existentes para a promoção de novos estilos de vida intrinsecamente sustentáveis (MANZINI, 1994).

\section{O Design e o Desenvolvimento Sustentável}

O Relatório de Brundtland, elaborado em 1987 pela Comissão Mundial sobre Meio Ambiente e Desenvolvimento, exemplifica o desenvolvimento sustentável em atos que satisfaçam as necessidades presentes da sociedade sem comprometer o futuro do planeta e das gerações futuras.

Nesse contexto, o design, conforme Löbach (2001), para os próprios designers, é um processo de resolução de problemas atendendo às necessidades do homem com o seu ambiente técnico, podendo ser encarado também como interferências e adaptações no ambiente "artificial" às necessidades físicas e psíquicas dos homens na sociedade.

Essas definições propõem que o designer está em contato direto com o ambiente, pessoas e também com a economia, através do desenvolvimento tecnológico e cultural, resultando no importante papel a ser desempenhado pelos mesmos como geradores de intervenções e mudanças.

Sendo assim, o ampliado escopo de atuação em que o design encontra-se, o faz capaz de interferir, de forma positiva, nas principais questões de cunho social, ambiental e econômico, transitando entre essas três dimensões, a fim de gerar equilíbrio entre elas. 
Design de sistemas - Visão Sistêmica - Inovação Sistêmica

Vezzoli (2007) apresenta o conceito "sistema de satisfação" como um dos aspectos mais relevantes para uma atuação sistêmica e, isto implica no desenvolvimento de soluções orientadas à satisfação das pessoas e não, necessariamente, bens físicos. Neste caso, o design busca ir além do que simplesmente a forma e a função, aqui a ênfase consiste no desenvolvimento de um sistema que resulte em satisfação.

Existem quatro níveis principais onde o design pode aturar para a sustentabilidade (MANZINI; VEZZOLI, 2002):

1. redesign ambiental dos produtos existentes;

2. projeto de novos produtos e serviços que substituam os atuais;

3. projeto de novos produtos e serviços intrinsecamente sustentáveis;

4. novos cenários que correspondam aos estilos de vida sustentável (Figura 3).

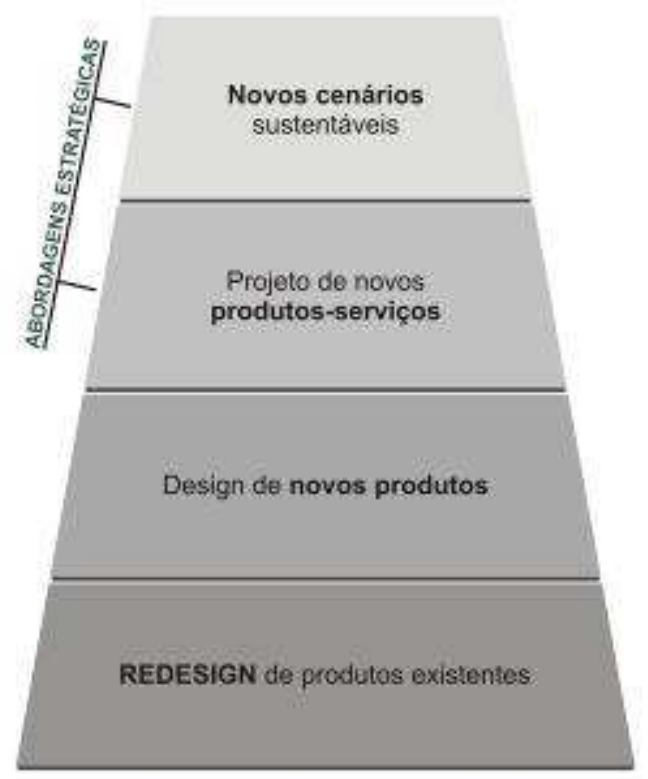

Figura 3 - Novos cenários do design

Fonte: Elaborado com base em Manzini e Vezzoli (2002)

Atualmente o design tem se apresentado como redesign de produtos, buscando aprimorá-los em busca de maior competitividade no mercado. Porém, o redesign pode ser voltado à eficiência no consumo de matéria-prima e energia e, facilitar a reciclagem e reuso dos componentes.

Este primeiro nível de atuação do design para a sustentabilidade tem potencial de atuação imediata. Nesse caso, não há necessidade de mudanças reais no estilo de vida e consumo, mas cria-se uma maior sensibilização em relação à escolha de produtos mais ambientalmente responsáveis (MANZINI; VEZZOLI, 2002).

Já o projeto de novos produtos e serviços que substituam os atuais pode gerar ganhos sócio-ambientais mais relevantes do que aqueles com foco apenas em produtos. Este nível de atuação exige que haja aceitação social e reconhecimento quanto à validade de novas proposições.

Tendo em vista a proposição de novos cenários sustentáveis, isto implica na promoção de critérios de qualidade no plano cultural, buscando a modificação do modo 
como são esperados os resultados, tanto por parte das empresas quanto por parte dos consumidores. Nesse momento, o designer possui um papel de grande relevância, porém há dependência de outras esferas de decisão, sejam elas políticas, empresariais ou mesmo da sociedade organizada (MANZINI; VEZZOLI, 2002).

Uma expressão que tem sido bastante utilizada nas discussões científicas nos últimos anos, como uma interpretação mais precisa da sustentabilidade, é o termo "Sistemas de inovação" ou "Design de sistemas eco-eficientes".

Vezzoli (2007), afirma que esta nova dimensão do design diz respeito a mudanças profundas nos modelos de consumo e produção e no estilo de vida atual, pois se amplia além do escopo do produto, incidindo sobre todo o sistema de demanda, atendendo às necessidades e aos desejos do usuário, ao mesmo tempo em que promove o consumo "suficiente".

O debate sobre Sistemas de Inovação tem sido correlacionado ao termo "Sistemas Produto-Serviço" pelos pesquisadores em design. Neste caso, o PSS se apresenta como uma ampliação do escopo de atuação do design, pois se manifesta como o resultado de uma estratégia inovadora que se desloca da aquisição de produtos físicos para a aquisição de um sistema de produtos e serviços capazes de satisfazer às demandas requeridas (VEZZOLI, 2007).

O desenvolvimento de sistemas produto-serviço pode ser considerado como uma das intervenções de destaque neste nível do projeto, pois conforme defende Tischner e Verkuijl (2006), a maior diferenciação de um modelo de inovação baseado em PSS é uma efetiva transformação do comportamento sócio-cultural e dos padrões de utilização, visto que combina diversos elementos heterogêneos como: aspectos culturais, pessoas, artefatos tecnológicos, transformações organizacionais e novas tecnologias.

Tanto a consolidação quanto a prática dos sistemas de inovação ainda se encontram em fase de experimentação, pois a implementação desses sistemas requer mudanças imprescindíveis e essas mudanças, segundo Mont (2000), passam em primeiro lugar pela superação da tradicional inércia de todos os interessados na aceitação, na adoção e na utilização de novos produtos e/ou serviços.

Os tradicionais domínios do design tem se expandido para além das características estéticas e funcionais do produto e, segundo Morelli (2002), se estendem para a observação e interferência nos fenômenos socioambientais e econômicos a fim de propor novos cenários plausíveis, baseados em elementos reais.

Os novos domínios do design buscam inovar e variar no que se refere às competências associadas ao seu escopo de trabalho, permitindo sua ampliação, como demonstrado na figura 4. (MORELLI, 2002). Nesse contexto, Manzini (2004) ressalta o papel fundamental do designer na construção de cenários inovadores direcionados para a sustentabilidade. 


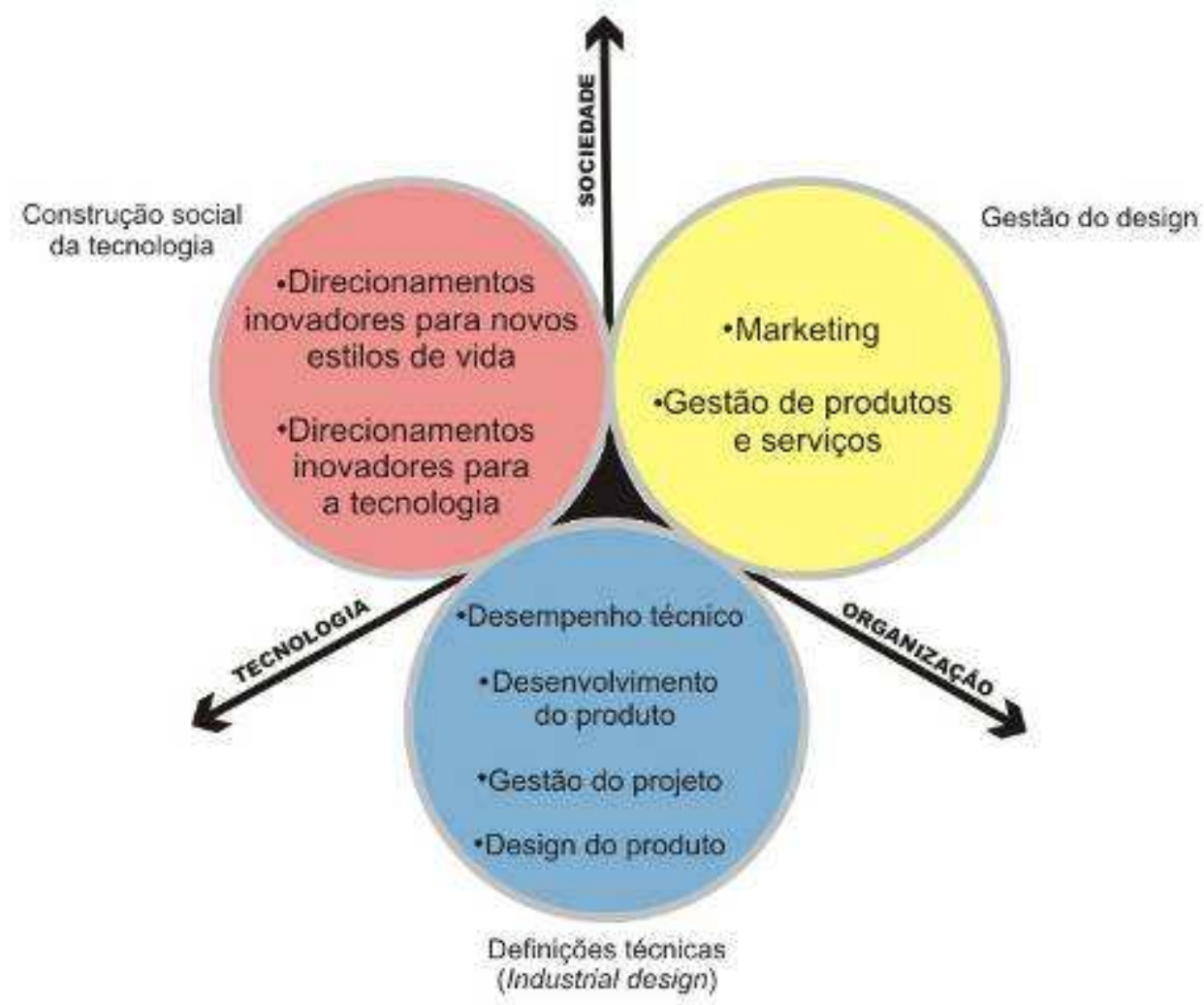

Figura 4 - Novos domínios do design Fonte: Morelli (2002)

No entanto, Manzini e Vezzoli (2002) observa que a transição para uma sociedade sustentável requer um longo e complexo processo coletivo de aprendizagem, no qual (além do designer) cada ator social terá de desempenhar um importante papel, adquirindo novas capacidades e assumindo novas responsabilidades de atuação. Porém, o autor defende a validade do papel da pesquisa em design em relação à produção de sistemas educativos, ferramentas e métodos direcionados para uma nova geração de educadores e designers, que lhes permita enfrentar de forma mais eficaz a transição para uma sociedade sustentável.

\section{Boas práticas sustentáveis}

Existem inúmeros mecanismos indutores de boas práticas sustentáveis nos diversos setores da sociedade. Para cada área de atuação, é possível identificar mecanismos específicos.

O Instituto Ethos (2006), selecionou algumas das principais fontes de referência dessas boas práticas. São elas: Iniciativas globais; direitos humanos; direito das relações de trabalho; proteção das relações de consumo; meio ambiente; governança corporativa e, implementação de responsabilidade social empresarial. Cada uma delas apresenta mecanismos indutores de boas práticas específicos: Agenda 21; Princípios do Global Compact; Objetivos de Desenvolvimento do Milênio (ODM); Carta da Terra; Convenção da ONU contra corrupção; Declaração Universal dos direitos humanos; AS 8000 - Social Accountability; Guia de Normas Internacionais do Trabalho; OHSAS 18001 - Occupational Health Safety Assessment Series; The Natural Step (TNS); Convenção sobre Diversidade 
Biológica (CDB); Declaração do Rio sobre Meio Ambiente e Desenvolvimento; Princípios do FSC; Série ISO 14000; Convenção de Viena para a Proteção da Camada de Ozônio; Convenção de Estocolmo sobre os Poluentes Orgânicos Persistentes; OCDE - Princípios de Governança Corporativa; IBGC - Código das Melhores Práticas de Governança Coporativa; Balanço Social Ibase; AA 1000; Indicadores Ethos; Diretrizes para Relatórios de Sustentabilidade da Global Reporting Initiative (GRI) e ABNT-NBR 16001:2004 - Norma Brasileira: Responsabilidade Social (Figura 5).

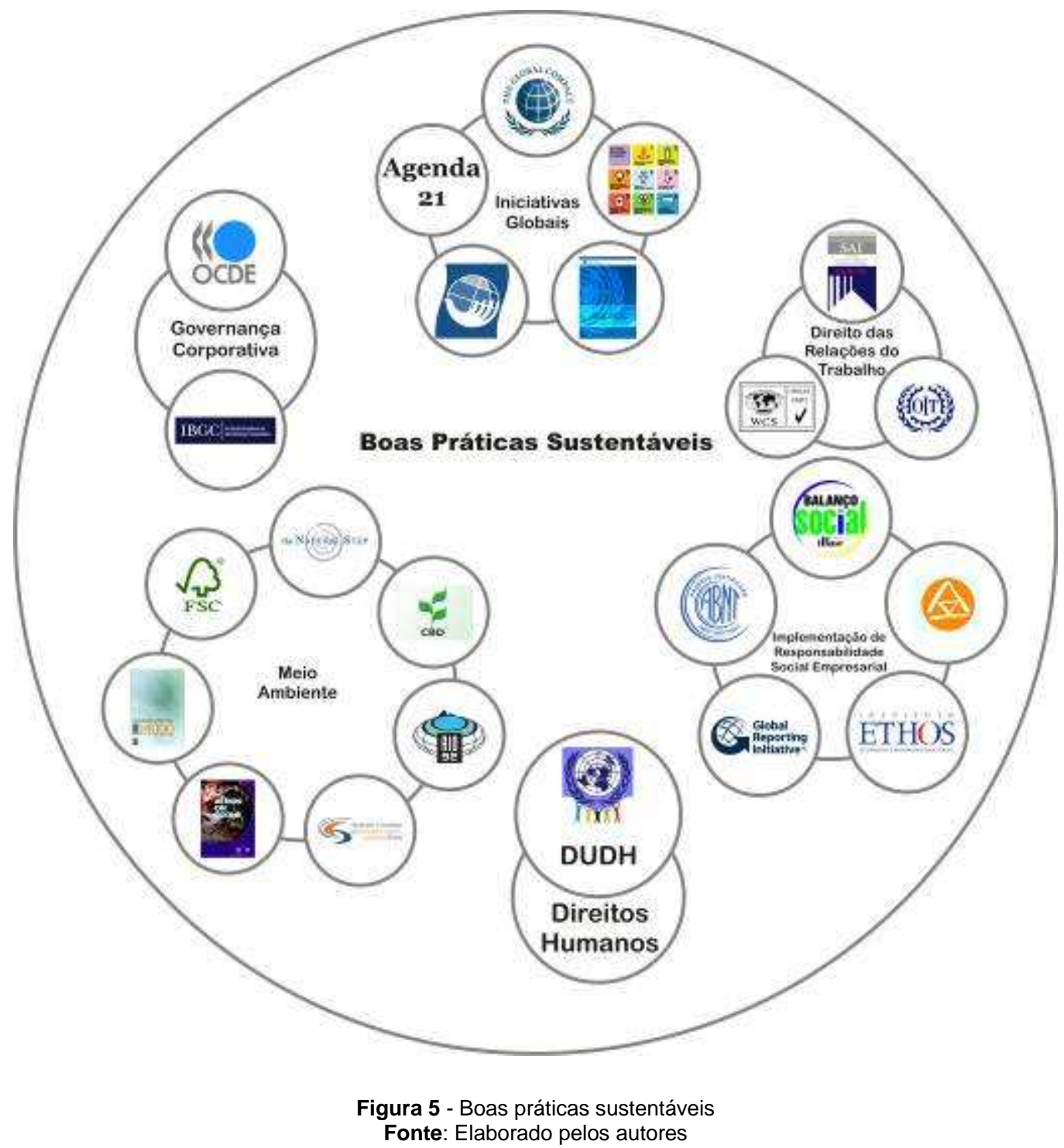

Conforme os mecanismos apresentados, através da interdisciplinaridade conferida ao design, os designers têm condições de abordar práticas de diferentes áreas de atuação, adaptando-as ao seu escopo de trabalho.

E, mesmo utilizando-se de mecanismos das diversas áreas de atuação, o design, gradativamente, conquista seus próprios mecanismos indutores de boas práticas sustentáveis. Entre eles, o EcoDesign Innovation - Professional Practice Guidelines (RMIT, 2010); EcoRedesign - Improving the environmental performance of manufactured products 
(RMIT, 2010); Greenfly Online (RMIT, 2010); Open IO (UARK - University of Arkansas 2010); Okala - Learning Ecological Design (IDSA - Industrial Designers Society for America, 2010).

O grande objetivo desses mecanismos é incentivar e auxiliar empresas e organizações na mudança de comportamento em todos os setores das mesmas, abrangendo desde os altos cargos da direção até os funcionários.

É possível que se aplique simultaneamente diversos mecanismos, de forma que um complemente o outro. É importante que as organizações acompanhem tais mecanismos não só como política interna, mas como uma forma de melhorar sua convivência com os diversos stakeholders (partes interessadas) que se inter-relacionam.

Em suma, a adoção de boas práticas traz muitos benefícios às organizações. Adotar uma gestão ética, transparente e comprometida com os relacionamentos que estabelece com todas as partes interessadas se torna um compromisso que, cada vez mais, ampliam o movimento da responsabilidade ambiental, social e econômica no país. Construir diálogos que considerem as expectativas dos diferentes públicos e implementar ações capazes de gerar valor para as pessoas, para o meio ambiente e para a sociedade como um todo, é o desafio hoje enfrentado. Desafio esse que demanda, dentre outras coisas, a utilização de ferramentas, critérios e indicadores que orientem uma gestão sustentável (INSTITUTO ETHOS, 2006).

\section{Panorama atual da sustentabilidade inserida nos campi universitários}

O debate sobre sustentabilidade provocou nos últimos anos diversas iniciativas voltadas para a preservação do meio ambiente por parte das organizações. Esse debate tem começado a incitar, também nas instituições de ensino superior, uma reflexão sobre seu papel e a busca por iniciativas que permitam criar campi universitários social e ambientalmente responsáveis (LAHAISE, 2010).

Embora a sustentabilidade e a responsabilidade socioambiental estejam presentes no debate acadêmico, ainda são poucos os casos em que esses temas são incorporados de forma orgânica ao funcionamento das escolas (SANTOS, 2009). Porém, conforme Tauchen e Brandli (2006), a consciência ecológica tem vindo a envolver diferentes camadas e setores da sociedade mundial, de que são exemplo as Instituições de Ensino Superior (IES). E, para os autores, as universidades e outras IES precisam praticar aquilo que ensinam. Desde o início da década de 90, estas instituições estão percebendo de que não poderão incutir valores ambientais aos alunos se elas próprias não os acatarem.

Ao quotidiano das IES estão associados grandes consumos de energia, de água e substâncias químicas, bem como a produção de grandes quantidades de resíduos sólidos e resíduos perigosos, como os resíduos químicos. Estas instituições são também grandes produtoras de efluentes líquidos, geralmente constituídos por elevadas cargas orgânicas e substâncias químicas, provenientes dos laboratórios (LOPES et al., 2005).

Para além destas características das instituições, também o transporte de e para os campi universitários acarreta impactos ao nível do ruído, do tráfego rodoviário e da poluição atmosférica das comunidades onde se encontram (LOPES et al., 2005).

Deste modo, as IES se encontram em posição privilegiada para melhorar o seu comportamento ambiental, pois, se por um lado são geradoras de problemas ambientais, por outro lado dispõem do conhecimento e competências necessárias para abordar esses mesmos problemas (GRAEDEL, 2002). 
O papel das IES rumo ao desenvolvimento sustentável divide-se em duas vertentes: primeiro, a questão educacional e a responsabilidade destas instituições na formação dos futuros tomadores de decisão (são consideradas "promotoras do conhecimento"); segundo, a implementação de Sistemas de Gestão Ambiental (SGA) nos seus campi universitários como modelos e exemplos práticos de gestão sustentável para a sociedade (Tauchen e Brandli, 2006).

Graedel (2002), constatou o fato de estas instituições serem receptivas a novas ideias, mais do que qualquer outra instituição na sociedade, defendendo que, por este motivo, a sustentabilidade pode ser mais facilmente alcançada numa IES do que nas outras instituições.

Manzini e Vezzoli (2002), apontam a educação ambiental como sendo um pilar do desenvolvimento sustentável, pois contribui para integrar a humanidade no ambiente e desperta nos indivíduos e grupos sociais organizados o desejo de participar na construção da sua cidadania. As IES podem, portanto, contribuir para o desenvolvimento de uma sociedade sustentável e justa, na medida em que desempenham um papel importante no processo de desenvolvimento tecnológico, na preparação de estudantes e no fornecimento de informações e conhecimento (TAUCHEN; BRANDLI, 2006).

As Universidades e outras IES reúnem com êxito o conhecimento local e global, as qualidades de docentes, estudantes e restante pessoal, criando sinergias com potencial de desenvolvimento de novas soluções (OWENS; HALFACRE-HITCHCOCK, 2006). Os autores entendem que, sabendo como promover a sustentabilidade a esta escala, é possível perceber como difundir os princípios de sustentabilidade por toda a sociedade, como demonstra a Figura 6.

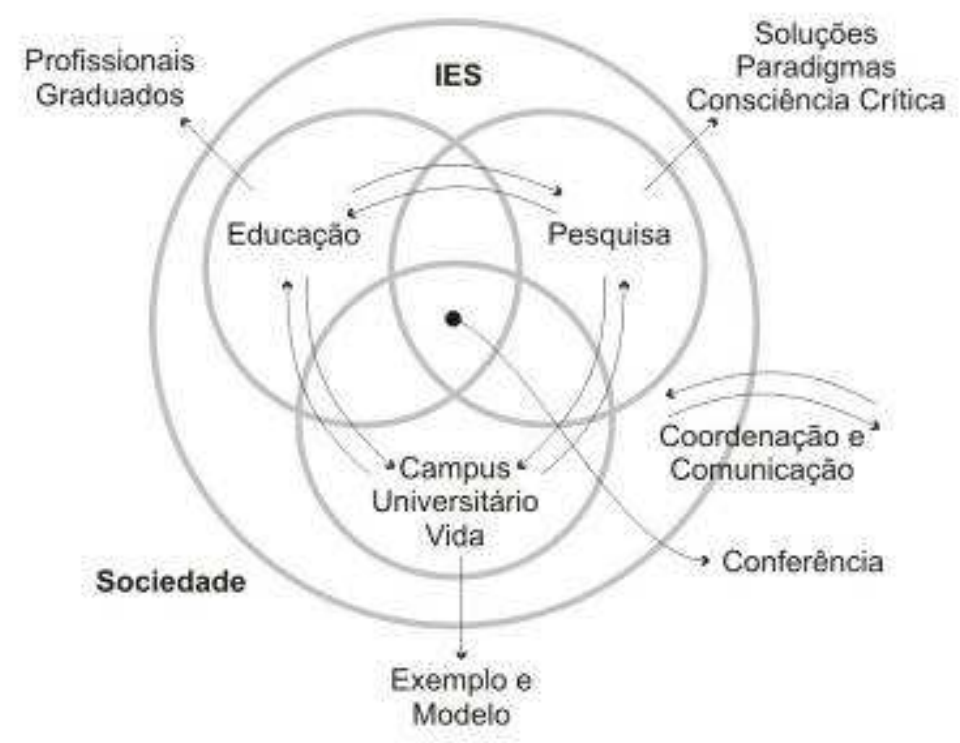

Figura 6 - Importância da IES na sociedade Fonte: Elaborado com base em Tuachen e Brandli (2006).

Entende-se por Universidade sustentável uma instituição de ensino superior, como o todo ou uma parte, que trata, envolve e promove, a nível regional ou global, a minimização dos impactos ambientais negativos, econômicos, sociais, de saúde e os efeitos 
gerados na utilização dos seus recursos com vista a cumprir a sua função de ensino, pesquisa, parceria e administração de forma a ajudar a sociedade a fazer a transição para estilos de vida sustentáveis (VELAZQUEZ et al., 2006). No entanto, o papel da Universidade não deve ser apenas este, deve avançar por um caminho de melhoria para além dos seus próprios limites.

O desenvolvimento sustentável é o grande desafio das Universidades no século XXI. Com a existência de diversas interpretações a este respeito, as estratégias utilizadas pelas Universidades para alcançar este desenvolvimento estão desde estabelecerem princípios, assinarem declarações, assumirem políticas ambientais, implementarem práticas e procedimentos, até desenvolverem levantamentos ambientais (LAHAISE, 2010).

Sabe-se que o mundo atual atravessa sérios problemas econômicos, sociais e ambientais que requerem novas soluções, novos conhecimentos e novas formas holísticas de pensamento (KAZAZIAN, 2005). Nesse sentido, as instituições de ensino estão bem posicionadas para oferecer.

Estas organizações têm o talento e a objetividade para avaliar as questões de sustentabilidade de importância crítica e a credibilidade para dirigir ações públicas nesta área. São elas que ensinam os futuros decisores, que lhes promovem a informação, as ferramentas e as competências essenciais para um bem comum a longo prazo. Este é o papel das instituições acadêmicas - o seu imperativo moral (BLACKBURN, 2007).

\section{Ferramentas voltadas para um campus sustentável}

Devido à relevância do tema, é possível encontrar algumas ferramentas específicas para a avaliação de um campus universitário sob os aspectos sustentáveis. Percebe-se, portanto, a possibilidade/necessidade de ampliar tal discussão.

Para exemplificar a crescente demanda por abordagens sustentáveis em campi universitários, serão apresentadas cinco ferramentas desenvolvidas com o objetivo de avaliar e/ou incentivar uma mudança de comportamento na comunidade acadêmica e no seu entorno no que se refere às boas práticas sócio-ambientais.

- Sustainability Assessment Questionnaire (SAQ) for Colleges and Universities - A ULSF (University Leaders for a Sustainable Future), dos Estados Unidos, elaborou um questionário que mensura o envolvimento de instituições de Ensino Superior com a sustentabilidade. O SAQ (Questionário de Avaliação Sustentável) avalia sete itens: currículo; pesquisa e bolsas de estudo; operação; desenvolvimento de corpo docente; serviço; oportunidades para estudantes; e administração, missão e planejamento (ULSF, 2002).

- Proposta de indicadores de sustentabilidade do programa USP Recicla - tem objetivo de inventariar o consumo e descarte de insumos (entradas e saídas) nos campi da Universidade de São Paulo; padronizar mecanismos de obtenção de dados do Programa USP Recicla; medir impactos das ações do Programas Socioambientais nos campi e em toda a USP; contribuir para o estabelecimento de metas de curto, médio e longo prazos; possibilitar visão de longo prazo e contribuir para a criação de políticas de sustentabilidade socioambiental para a USP (USP, 2010).

- Programa Campus Sustentável - trata-se de uma iniciativa da Coordenadoria do Campus da Capital do Estado de São Paulo - COCESP. Este plano está configurado em três eixos estruturais: infraestrutura adequada para a sustentabilidade; 
qualidade de vida obtida a partir de ações sustentáveis e gestão participativa/transparência. As atividades propostas estão ligadas por estes eixos e transversalmente entre si. As atividades são totalmente interdependentes, com relações intrínsecas entre si, que necessitam ser estudadas e analisadas cuidadosamente para serem desenvolvidas. Para isto, se faz necessário o planejamento e a realização de investigações diagnósticas permanentes e regulares. É importante ressaltar que o Programa foi concebido com o objetivo de tornar o Campus uma área de produção e experimentação de conhecimento e também de apoio educacional (COCESP, 2010).

- Principles for Responsible Management Education - PRME - princípios para uma educação responsável em gestão que surgiram por iniciativa do Pacto Global das Nações Unidas e foram desenvolvidos em 2007 por representantes de 60 das maiores escolas de administração do mundo. Duas instituições brasileiras participaram da sua elaboração: o Instituto Superior de Administração e Economia da Fundação Getulio Vargas (ISAE/FGV) e a Fundação Dom Cabral. Trata-se de seis princípios que têm por finalidade funcionar como fonte de inspiração e de conduta para líderes universitários se engajarem em um processo de melhora contínua da gestão educacional, a fim de formar líderes empresariais capazes de enfrentar de forma responsável os complexos desafios ambientais e sociais do século XXI. Entre as instituições com legitimidade internacional que hoje endossam o documento final do PRME, destacam-se: The Association to Advance Collegiate Schools of Business (AACSB), European Foundation for Management Development (EFMD), European Academy of Business in Society (EABIS), Globally Responsible Leadership Initiative (GRLI) e Net Impact (PRME, 2010).

- Campus Sustainability Assessment Framework - CSAF - trata-se de um projeto canadense apoiado pela Sierra Youth Coalition (SYC), entidade fundada e dirigida por jovens, cuja missão é capacitar os estudantes canadenses e formar líderes comunitários ativos, que contribuam para o desenvolvimento de uma sociedade sustentável. Iniciado formalmente em 1998, quase nove anos antes do PRME, o projeto de campi sustentáveis tornou-se rapidamente uma iniciativa nacional do Canadá que inspira, informa, treina e apóia estudantes a trabalharem por campi universitários mais igualitários socialmente, íntegros ecologicamente e economicamente prósperos (COLE, 2003).

\section{Recorte Ambiental}

Tendo em vista a multiplicidade e complexidade dos aspectos a serem considerados em uma análise de sustentabilidade de um campus universitário, este projeto teve seu escopo de trabalho delimitado à dimensão ambiental. Contudo, é importante ressaltar que muitas das diretrizes ambientais acabam tendo implicações sociais e econômicas como, por exemplo, melhoria da condição de vida; aumento da rentabilidade e credibilidade; um maior diálogo entre a sociedade e as universidades, entre outros.

O objeto de estudo compreende abordar as atividades realizadas em um campus universitário com ênfase nas questões ligadas à dimensão ambiental da sustentabilidade, embora na análise sejam consideradas também a dimensão econômica e social. O recorte ambiental compreende, principalmente, os "inputs" (aspectos de entrada) que são: água, 
energia e materiais; "outputs" (aspectos de saída) que são: atmosfera e geração/destinação de resíduos; e aspectos relativos às instituições de ensino superior: educação ambiental, biodiversidade, pesquisa, extensão e comunicação. Para ilustrar as atividades realizadas em um campus universitário foi desenvolvido um mapa mental (Figura 7).

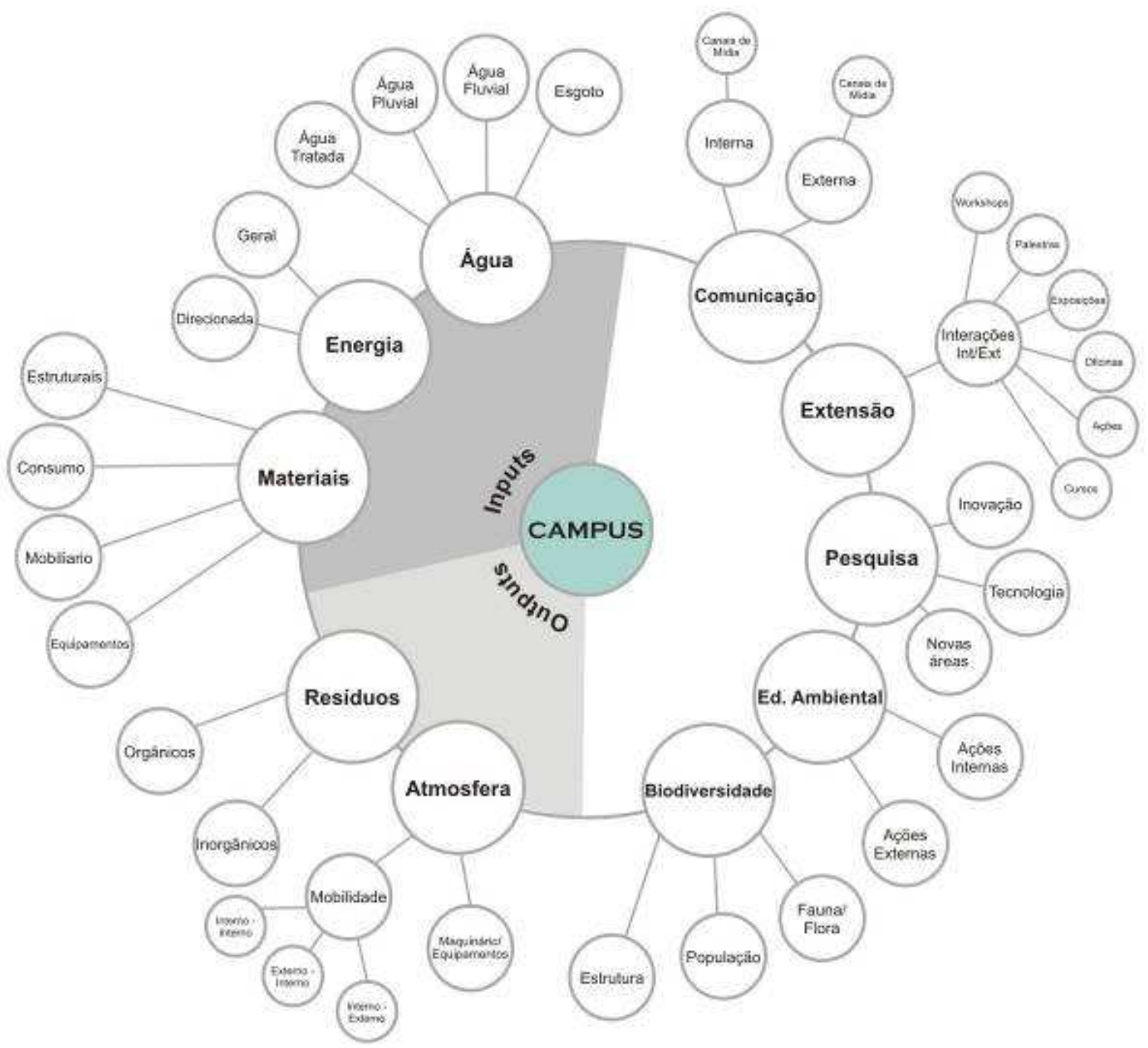

Figura 7 - Mapa mental das atividades em um campus universitário

Os dados coletados nesta pesquisa são baseados em uma análise de sete campi universitários dos seguintes continentes: Ásia, Africa, Oceania, América e Europa.

\section{Cases de Universidades}

Após um levantamento preliminar de iniciativas de sustentabilidade em universidades brasileiras e estrangeiras, foram escolhidas sete instituições que apresentam projetos relacionados à sustentabilidade nos seus campi. Em seguida, foi feita uma pesquisa qualitativa com estas universidades utilizando-se como ferramenta principal a pesquisa junto aos próprios websites destas instituições. 
As instituições pesquisadas são: Universidade Positivo (Brasil) e Universidade de São Paulo (Brasil) da América do Sul, University of Arkansas (EUA) da América do Norte, Universidad Autónoma de Madrid (Espanha) da Europa, Royal Melbourne Institute of Technology (Australia) da Oceania, University of Tokyo (Japão) da Ásia e University of Cape Town (África do Sul) da África (Figura 8). A pesquisa consiste em desenvolver um quadro comparativo entre as instituições de ensino superior citadas, e uma matriz de impacto, contemplando as instituições e as ações nelas ocorridas.

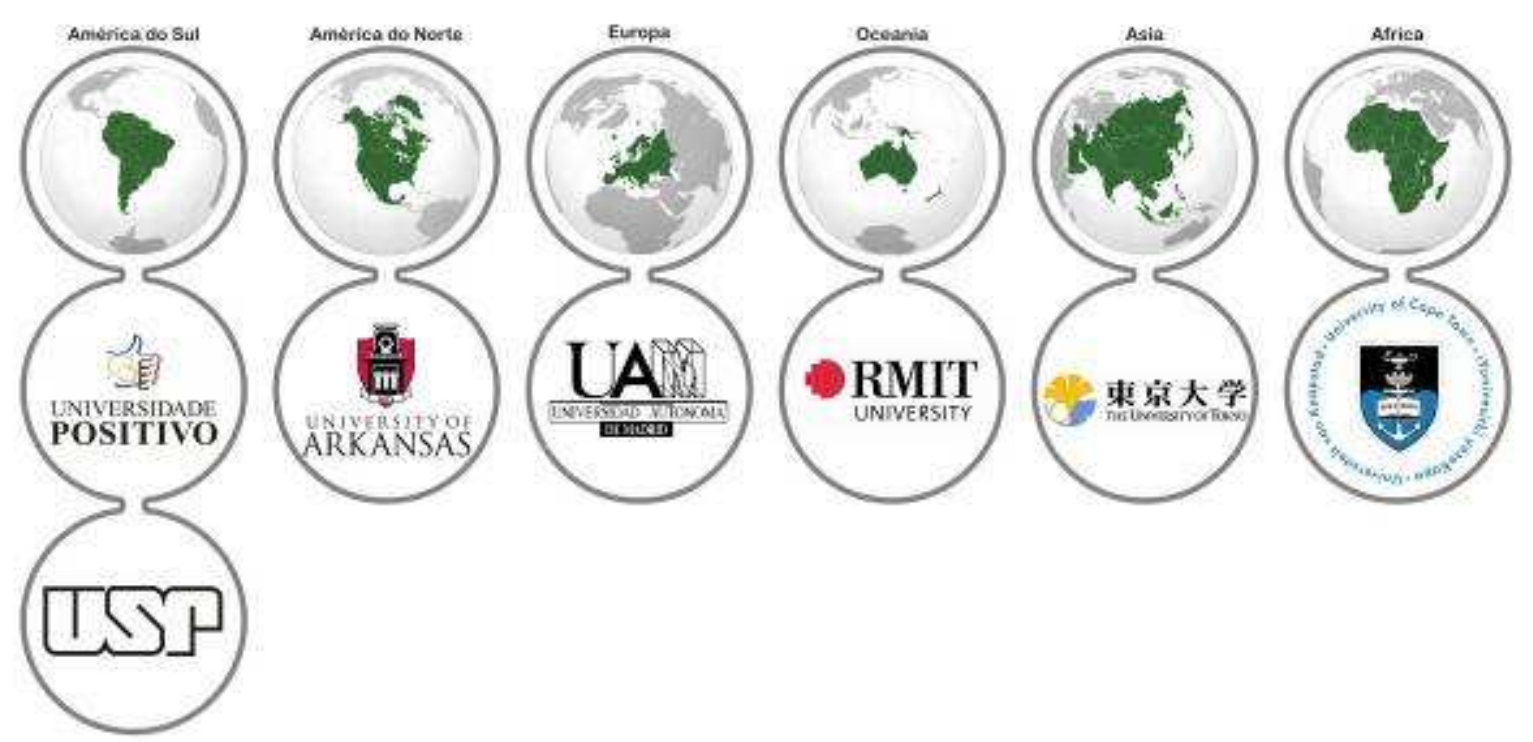

Figura 8 - Universidades pesquisadas por continentes

Para melhor visualização e entendimento, a pesquisa dos cases foi dimensionada em um quadro comparativo (Figura 9), contendo um resumo das ações, na dimensão ambiental da sustentabilidade, exercidas por cada instituição de ensino superior, bem como os pontos positivos e negativos avaliados. 


\begin{tabular}{|c|c|c|c|}
\hline $\begin{array}{l}r \\
\text { PONIFESITIVE } \\
\text { POSITIVO }\end{array}$ & 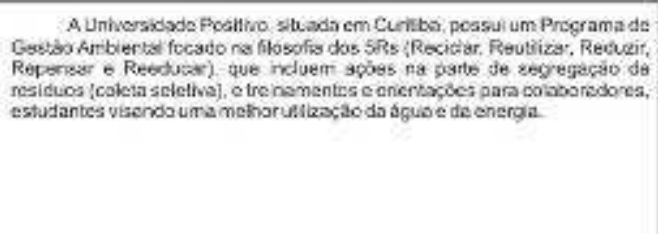 & 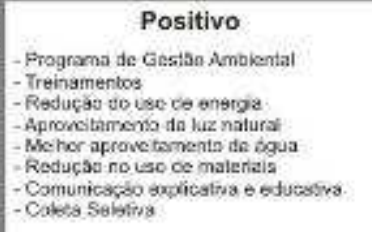 & 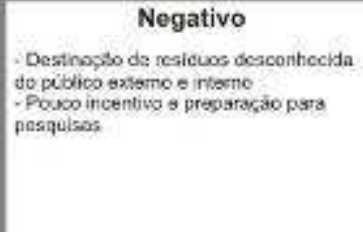 \\
\hline & 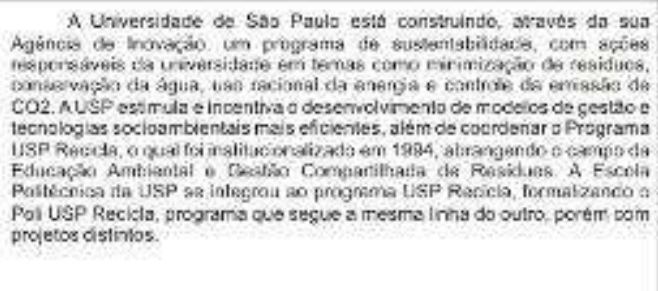 & 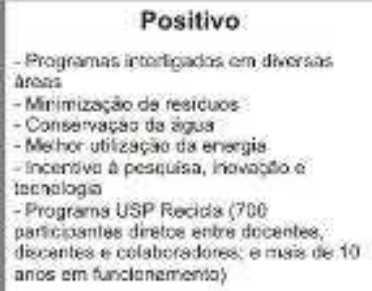 & 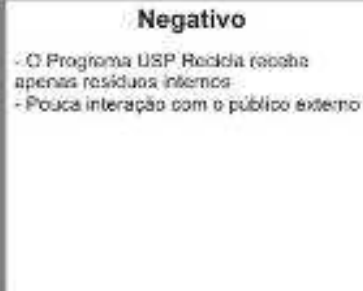 \\
\hline $\mathscr{S}$ & 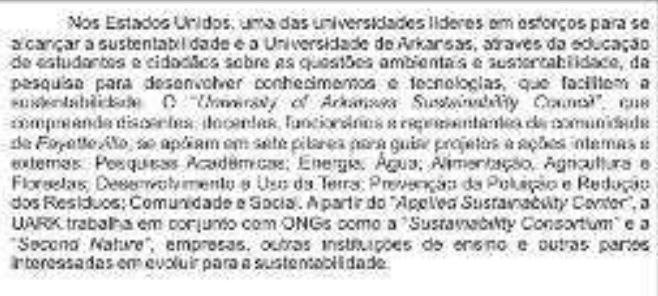 & 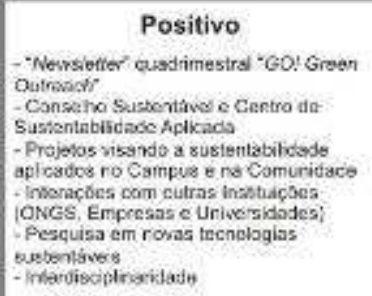 & 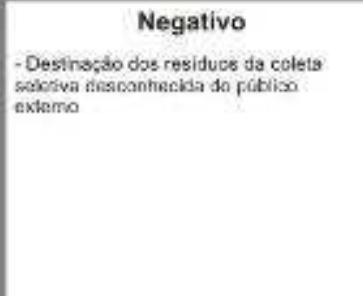 \\
\hline & 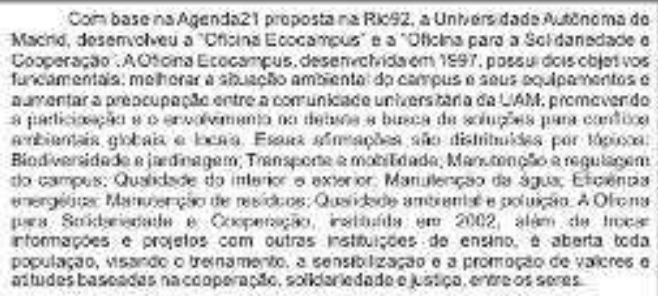 & 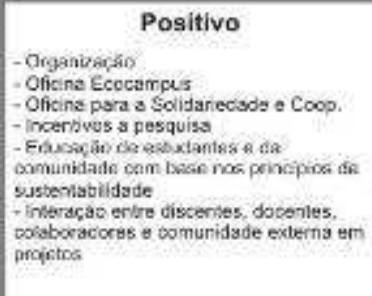 & 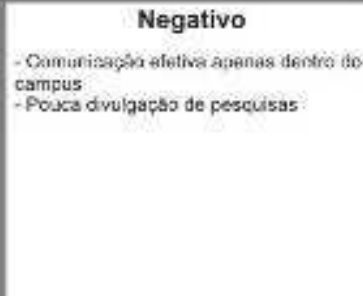 \\
\hline & 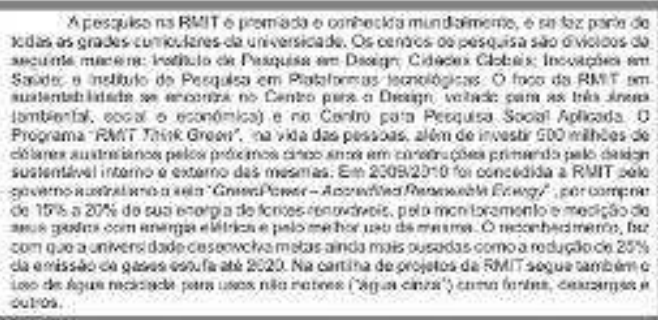 & 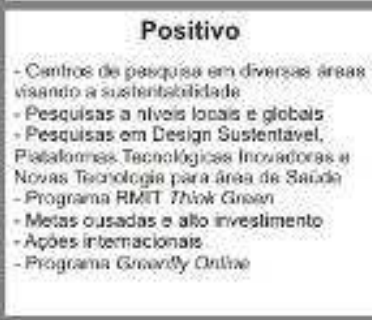 & 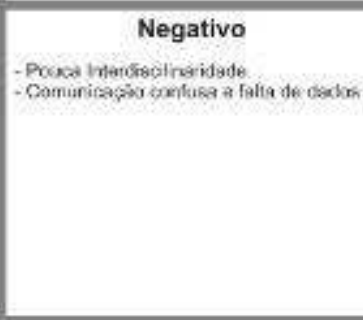 \\
\hline & 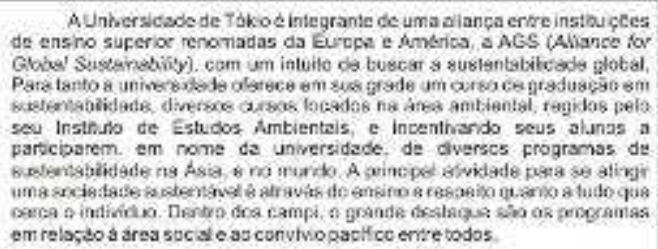 & 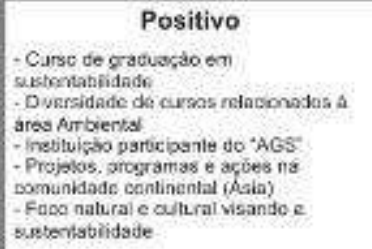 & 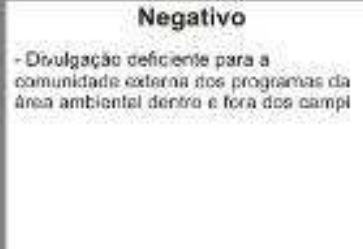 \\
\hline & 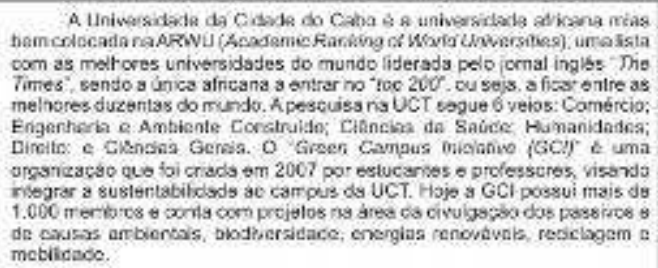 & 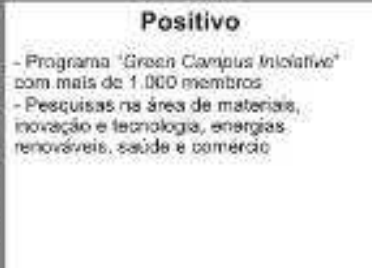 & 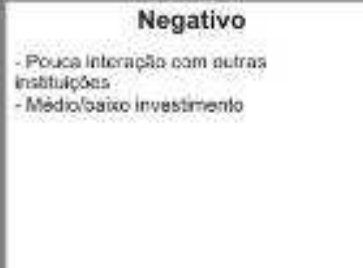 \\
\hline
\end{tabular}

Figura 9 - Quadro comparativo de universidades 
A partir do exposto, constata-se que todas as universidades têm aspectos a serem melhorados e outros a serem incentivados e continuados. Para melhor visualização dos pontos críticos, bons e ótimos, foi desenvolvida uma matriz de impacto (Figura 10), cruzando dez pontos: Água, Energia e Materiais ("inputs"); Atmosfera e Resíduos ("outputs"); Biodiversidade; Educação Ambiental; Pesquisa; Extensão; e Comunicação, com as instituições em questão.

A matriz de impacto, proveniente da metodologia D4S, foi adaptada para a melhor utilização. Os itens que a compõe foram alterados para suprir as necessidades da presente pesquisa.

Os critérios que medem o nível de impacto das ações foram classificados com base no quadro comparativo das universidades pesquisadas (vide p. 13) e no Mapa Mental (vide p. 11). A Matriz de Impactos, nesse caso, serve para a melhor visualização dos resultados obtidos.

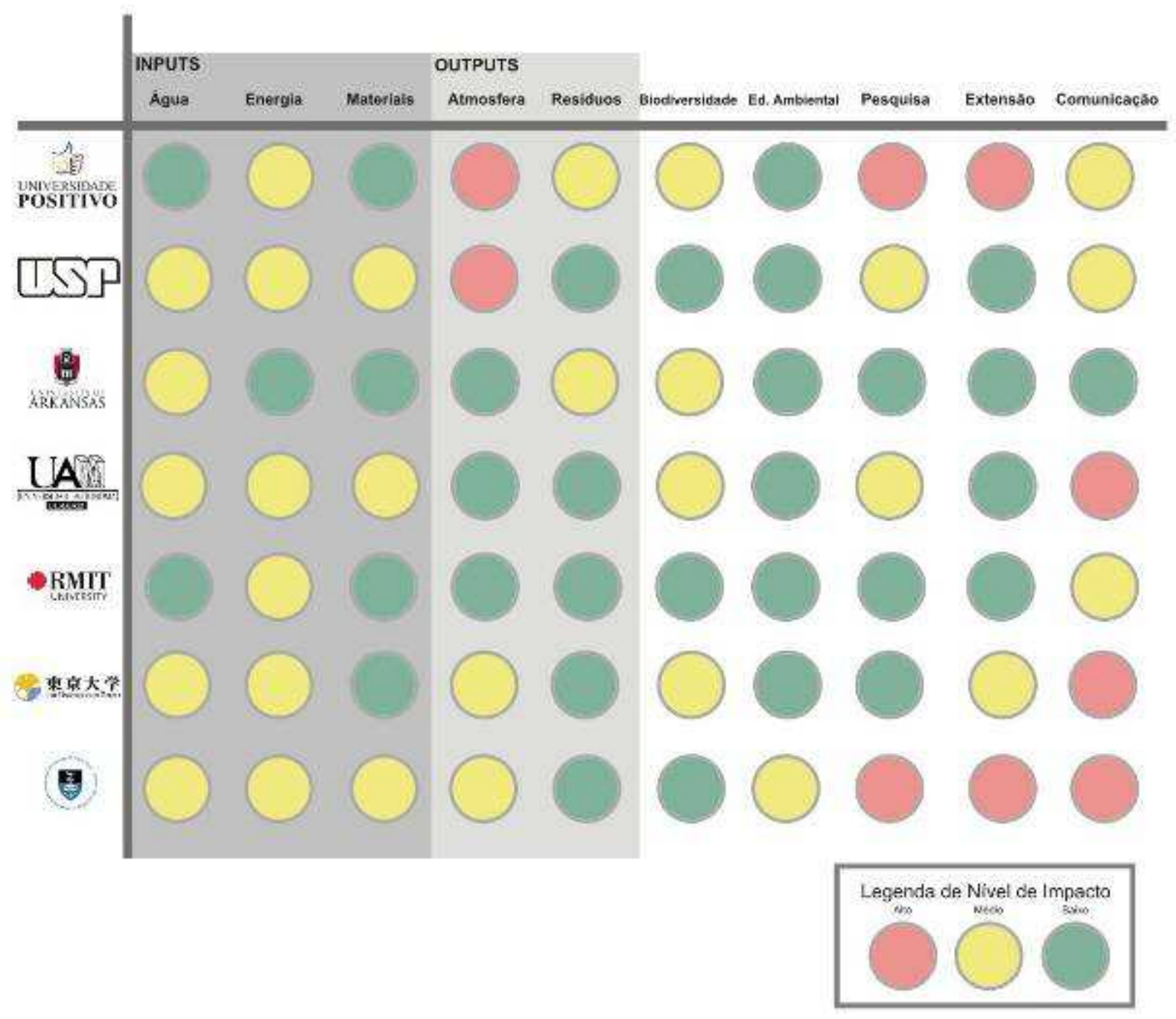

Figura 10 - Matriz de Impacto

Fonte: Elaborado com base nas ferramentas do D4S (2010) 


\section{Análises}

A partir da matriz de impacto, levando em conta que os países onde estão as instituições pesquisadas possuem situações econômicas e sociais distintas, pode-se observar que a ação comunicação necessita de melhoramentos para que todos (comunidade externa, comunidade interna) fiquem a par e possam se inteirar e até mesmo participar de projetos. A pesquisa pode ser sempre incentivada no meio acadêmico, mesmo que com recursos limitados, há possibilidade de avanço em todas as áreas ligadas à sustentabilidade ambiental e, englobando todas as ações descritas na matriz.

A energia em diversos países, ainda em sua maioria, vem de fontes térmicas e nucleares, porém a as universidades se põem a buscar novos caminhos para a geração ou captação de fontes alternativas. A coleta seletiva e a correta destinação dos resíduos são reais e funcionam nas instituições de ensino superior pesquisadas, com diversos programas com muitos anos de funcionamento e o envolvimento de comunidades.

Em relação à atmosfera, a quantidade de automóveis que circulam nos perímetros das universidades ainda é um problema a ser resolvido, contemplando não só a universidade em si, mas a cidade na qual ela está inserida, porém muitas já apresentam soluções como vias apropriadas na cidade para bicicletas, bom transporte público, sistema integrado de caronas, entre outros.

A biodiversidade pode ser melhorada através de incentivos e ações nas instituições visando o convívio adequado entre os seres humanos, fauna, flora e estrutura. O melhor uso da água vem sendo implementado em alguns campi, com projetos visando o reaproveitamento de água "cinza", e a prevenção do desperdício.

As pesquisas e novas tecnologias em novos materiais, com ciclo de vida otimizado, que surgem nas universidades vem ganhando força, alavancados em parcerias com indústrias, empresas e a própria instituição.

O ensino na área da educação ambiental está numa crescente, com diversos novos cursos ligados à grande área ambiental, além do oferecimento de workshops, oficinas, exposições e palestras sobre o assunto que vem acompanhando a preocupação mundial com o meio ambiente, fazendo com que a extensão nas universidades que consigam captar recursos, ganhe força.

Para essas e outras ações que necessitam de melhoras urgentes e outras de crescimento melhorado e contínuo, o uso da metodologia do PSS permite, por meio de ferramentas especificas, propor novos cenários visando modificação da situação das ações, sejam elas saindo da estagnação ou por um melhoramento contínuo daquelas já estabelecidas.

\section{Análise SWOT}

Com o objetivo de detectar os pontos fortes e fracos dos atores envolvidos no sistema e as ameaças e oportunidades ligadas à atividade de cada um deles, foi feita uma análise SWOT (Strenghts, Weaknesses, Opportunities e Threats). O intuito é atuar no aprimoramento dos pontos fracos, na maximização dos pontos fortes, na minimização das ameaças e na exploração de novas oportunidades. Desta forma, para potencializar resultados e mapear ideias, foram analisadas as práticas ambientais existentes nos campi universitários já apresentados (Figura 11). 


\section{ANÁLISE SWOT}

\section{FORÇAS}

- Diversidade cultural e acadêmica

- Interdisciplinaridade

- Programa de Gestão Ambiental

- Comunicação

- Programas voltadas à sustentabilidade no Campus

- Interação Campus/Comunidade Acadêmica/Comunidade Externa/Parceiros

- Incentivo à Pesquisa

\section{OPORUTNIDADES}

- Sustentabilidade inserida na Grade Curricular

- Maior disponibilidade de cursos na área ambiental

- Comunicaçáo

- Inovação em P\&D*

\section{FRAQUEZAS}

- Deficiência da Comunidade Académica para P\&D*

- Inexisténcia/ineficiência de programas de Gestāo Ambiental

- Pouca interaçăo com o Público Externo

- Não promoção da interdsciplinaridade

- Ineficiência na comunicaçăo

- Baixo nivel de investimento

Figura 10 -Análise Swot

Fonte: Elaborado pelos autores

\section{Resultados}

Para elencar as melhores práticas ambientais a serem adotadas por um campus universitário, foi utilizada a ferramenta checklist (Figura 11). Os dados colhidos na presente pesquisa, na Matriz de Impactos e a Análise Swot, possibilitaram a triagem dessas melhores práticas. Esta ferramenta foi escolhida em função de viabilizar a indicação das práticas adotadas, ou não, pela universidade e, ainda, as práticas que podem ser melhoradas. 


\section{CHECKLIST AMBIENTAL}

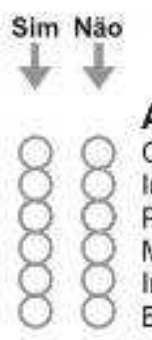

\section{Atmosfera}

Garantia e controle do cumprimento das leis locais e globais:

Indicadores de desempenho ambiental;

Reduçåo das emissỏes potencialmente poluentes:

Melhoria do desempenho ambiental:

Incentivo a mobilidade urbana diversificada;

Busca de fornecedores e parceiros locais (reduçäo do transporte)

\section{Água}

Garantia e controle do cumprimento das leis locais e globais

Indicadores de desempenho ambiental;

Uso consciente da água;

Captaçăo de águas pluviais:

Reutilizaçāo de "água cinza":

Instalaçăo de equipamentos para eficiente uso da àgua

;

\section{Energia}

Garantia e controle do cumprimento das leis locais e globais;

Indicadores de desempenho ambiental;

Uso consciente da energia,

Uso de fontes renováveis:

Busca por novas fontes renováveis

\section{Biodiversidade}

Garantia e controle do cumprimento das leis locais e globais;

Indicadores de desempenho ambiental;

Respeitar, preservar e fortalecer o ecossistema local:

Comunicação interna e externa visando um esforço conjunto

\section{Educação Ambiental}

Garantia e controle do cumprimento das leis locais e globais;

Adoçăo de boas práticas ambientais;

Aumento da comunicaçăo no interior dos campi e com as organizaçôes e/ou instituiçôes do exterior:

Compreensäo do aluno da sua capacidade de influenciar mudanças sistêmicas/comportamentais:

Meihoria e ampliação da gama de cursos voltados à área ambiental;

Inserçāo da sustentabilidade nas grades curriculares;

Interaçăo da comunidade académica com a comunidade externa:

Incentivo à pesquisa sobre a sustentabilidade

\section{Residuos}

Garantia e controle do cumprimento das leis locais e globais:

Indicadores de desempenho ambiental;

Programas de coleta seletiva:

Processamento do residuo organico (compostagem);

Processamento do residuo näo orgânico (reciclagem)

\section{Materiais}

Garantia e controle do cumprimento das leis locais e globais;

Indicadores de desempenho ambiental;

Fornecedores locais certificados ambientalmente;

PSS - Sistema Produto/Serviço:

Uso consciente de materiais;

Uso de materiais reciclados e recicláveis;

Extensăo da vida útil dos materiais:

Preferencia por materiais menos tóxicos

Figura 11 - Checklist de sustentabilidade nas universidades

Fonte: Elaborado pelos autores 
A relevância do tema aqui apresentado traz reflexões importantes não só para as instituições de ensino, mas também para a sociedade como um todo. É importante ressaltar a possibilidade da disseminação de boas práticas ambientais pelas universidades, tendo em vista a influência que estas exercem sobre a sociedade, construindo a educação de indivíduos formadores de opinião.

Para trabalhos futuros, esta pesquisa deixa algumas lacunas a serem supridas por outros estudos. As dimensões social e econômica são de grande relevância na busca pela sustentabilidade do campus, porém, devido à complexidade do tema e o tempo reduzido, optou-se por abordar apenas o recorte ambiental.

Considerando que a avaliação dos dados coletados para este projeto se dá de forma qualitativa, pois teve neste trabalho apenas a função de levantar as atividades realizadas nos campi universitários, comparar suas boas práticas ambientais e analisar, por meio das duas primeiras etapas do Mepss que consistem na Análise Estratégica e Exploração de Oportunidades, há que se avaliar estes dados, posteriormente, de forma quantitativa aprofundada. Futuramente, seria possível utilizar as ferramentas das fases posteriores do Mepss: Desenvolvimento do Conceito, Desenvolvimento do PSS e Implementação do PSS.

Para a adoção satisfatória das boas práticas e o melhoramento ambiental contínuo das universidades é necessário considerar a interação entre os stakeholders: comunidade acadêmica, comunidade externa, colaboradores internos, colaboradores externos, parceiros (ONG'S, empresas, indústrias, governo).

Para assumir a coordenação deste tipo de projeto é importante que o profissional tenha: pró-atividade; engajamento com a temática da sustentabilidade; visão sistêmica, com capacidade de compreender as diferentes inter-relações presentes em um sistema complexo como o campus universitário, bom network ou a capacidade de formá-lo e/ou expandi-lo; interatividade e relacionamento horizontal entre os atores.

A preocupação ambiental é global, não só local. Desta forma, estende-se aos distintos fatores sócio-econômicos e geográfico-culturais. Nesse sentido, a presente pesquisa buscou elencar, a partir de uma amostra reduzida a sete universidades, as melhores práticas ambientais de campi sustentáveis realizadas no mundo, onde cada universidade poderá adotar as melhores práticas ambientais cabíveis e possíveis a elas, dentro do seu contexto local.

É importante lembrar também que, para uma avaliação mais aprofundada dos dados ambientais coletados, é necessário que haja uma discussão entre os diferentes atores ligados ao sistema, neste caso, o campus universitário.

\section{Referências}

BARDAGLIO, Peter W. A moment of a Grace Integrating Sustainability into the Undergrade Curriculum. Planning for Higher Education, Ann Arbor, v. 36, n. 1, p. 16-22, 2007. Disponível em: <oneplanetfellows.pbworks.com/f/A\%2BMoment\%2Bof\%2BGrace.doc>. Acesso em: 10 set. 2010.

BLACKBURN, William R. The sustainability handbook. Washington: Environmental Law Institute, 2007.

BRUNDTLAND, Gro Harlem. Our common future. New York: WCED, 1987. 
COLE, Lindsay. CSAF: campus sustainability assessment framework. 2003. Disponível em: <http://www.sustainabilitysolutions.ca/downloads/15.\%20CSAF.pdf>. Acesso em: 10 nov. 2010.

COORDENADORIA DO CAMPUS DA CAPITAL DO ESTADO DE SÃO PAULO (COCESP). Programa campus sustentável. Disponível em: http://www.usp.br/cocesp/index.php?p=75\&f=146 Acesso em: 10 set. 2010.

GRAEDEL, Thomas E. Quantitative sustainability in a college or university setting. International Journal of Sustainability in Higher Education, Bingley, v. 3, n. 4, p. 346-358, 2002.

INDUSTRIAL DESIGNERS SOCIETY FOR AMERICA (IDSA). Okala - Learning Ecological Design Disponível em: <http://www.idsa.org/>. Acesso em: 12 nov. 2010.

INSTITUTO ETHOS. Critérios essenciais de RSE e seus mecanismos indutores. 2006. Disponível em: <http://www.ethos.org.br/_Uniethos/Documents/criterios_essenciais_web.pdf>. Acesso em: 10 set. 2010.

INTERNATIONAL COUNCIL OF SOCIETIES OF INDUSTRIAL DESIGN (ICSID). A partner of the international design alliance. Disponível em: <http://icsid.org/articles31.htm>. Acesso em: 28 ago. 2008.

KAZAZIAN, Thierry. Haverá a idade das coisas leves. Tradução de Eric Roland René Heneault. São Paulo: Ed. Senac, 2005.

LAHAISE, Catherine; POZZEBON, MARLEI. Campi sustentáveis. GV Executive, Rio de Janeiro, v. 9, n. 1, p. 30-35, jan./jun. 2010.

LÖBACH, Bernd. Design industrial: bases para a construção de produtos industriais. Tradução de Freddy Van Camp. São Paulo: Edgard Blücher, 2000.

LOPES, Marta; CARREIRAS, Manuela; FERREIRA, Antonio J. Diniz. A implementação de um SGA na ESAC: problemas e oportunidades. 2005. Disponível em: <http://www.esac.pt/emas@school/Publicacoes/Comunicacoes/CNA04/MLopes_com.pdf> Acesso em: 5 out. 2010.

MANZINI, Ezio. Design: environment and social quality: from "Existenzminimum "to" quality Maximum. Design, London, v. 10, n. 1, p. 37-43, 1994.

MANZINI, Ezio; COLLINA, Luisa; EVANS, Stephen. Solution oriented partnership: How to Design industrialised sustainable solutions. European Comission Growth Programme. Cranfield: Cranfield University, 2004.

MANZINI, Ezio; VEZZOLI, Carlo. O desenvolvimento de produtos sustentáveis: os requisitos ambientais dos produtos industriais. São Paulo: Edusp, 2002.

MEPSS. Methodology for product service system. Disponível em:< http://www.mepss.nl/>. Acesso em: 10 set. 2010 
MONT, Oksana. Product service systems. Lund: Lund University, 2000 (Final report IIIEE)

MORELLI, Nicola. The design of product/service systems from a designer's perspective. Sydney: University. Austrália/Centre for Design at RMIT, 2002.

OWENS, Katharine A.; HALFACRE-HITCHCOCK, Angela. As green as we think? the case of the College of Charleston green building initiative. International Journal of Sustainability in Higher Education, Bingley, v. 7, p. 114-128, 2006.

PRME. Principles for Responsible Management Education. Disponível em:<http://www.unprme.org/> Acesso em: 10 set. 2010.

ROYAL MELBOURNE INSTITUTE OF TECHNOLOGY (RMIT). RMIT University. Disponível em: $<$ http://www.rmit.edu.au/>. Acesso em: 10 set. 2010.

ROCHA LOURES, Rodrigo da Costa. Educar e inovar na sustentabilidade. Curitiba: UNINDUS, 194.

SANTOS, Filipa Maria Correia. Benchmarking ambiental e de sustentabilidade para campus Universitários caso de estudo da FCT-UNL. 2009. Dissertação (Mestrado) - Universidade Nova De Lisboa - Faculdade de Ciências e Tecnologia - Departamento de Ciências e Engenharia do Ambiente.

TAUCHEN, Joel; BRANDLI, L. Londero. A gestão ambiental em instituições de ensino superior: modelo para implantação em campus universitário. Gestão \& Produção, São carlos, v. 13, p. 503-515, 2006.

TISCHNER, Ursula; VERKUIJL, Martijn. Design for (social) sustainability and radical change. score, perspectives on radical changes to sustainable consumption and production. Delft, Holanda: TNO Built Environment and Geosciences, 2006.

UNIVERSIDADE DE SÃO PAULO (USP). Proposta de indicadores de sustentabilidade do programa USP Recicla. Disponível em: http://www.inovacao.usp.br/recicla/index.php Último acesso: 17 nov. 2010.

UNIVERSITY LEADERS FOR A SUSTAINABLE FUTURE (ULSF). Talloires declaration resource kit: a guide to promoting and signing the talloires declaration. Washington: Association of a University Leaders for Sustainable Future, 2002.

UNIVERSITY OF ARKANSAS (UARK). Open IO. Disponível em:<http://www.uark.edu/home/>. Acesso em: 10 set. 2010.

VELAZQUEZ, Luis; MUNGUIA, Nora; PLATT, Alberto; TADDEI, Jorge. Sustainable university: what can be the matter? Journal of Cleaner Production, Amsterdam, v. 14, p. 810-819, 2006.

VEZZOLI, Carlo. System design for sustainability: theory, methods and tools for a sustainable "satisfaction-system" design. Milano, Italy: Maggioli Editore, 2007. 